\title{
Legend for Editions and Translations
}

\section{Legends}

\section{Editions}

f jihvāmūlìya

A in diplomatic editions only, uppercase vowels represent full (initial) vowel forms in the original

$\mathrm{T}$ in diplomatic editions only, uppercase consonants represent final (halanta) consonant forms in the original

_ space in original, approximately one character width in extent

I generic punctuation character (appearance described under Script and language for each inscription)

\| higher-level punctuation character when more than one type is used in the original (appearance described under Script and language for each inscription)

$\S$ other symbol, e.g. siddham sign or ornamental mark (described in note to the text)

\section{structural features}

[1] line number, indicates beginning of line

[A] indicates beginning of other physical unit, e.g. fragment

(1) verse number, indicates beginning of verse in diplomatic text shown in curated text as a header, e.g. 〈Verse 1. Metre: anuștubh〉

() unclear text: some damage to substrate or unusual or erroneous shape

(abc) unclear but confidently read in context

(?abc) unclear and tentatively read

$(\mathrm{a} / \mathrm{b}) \quad$ unclear text with ambiguous readings deemed possible

[] lacunae: characters illegible due to damage, or substrate altogether lost

$\times$ lost consonant (or conjunct) followed by a legible or restored vowel

[...] lacuna of unknown extent

[1] lacuna, extent stated in number of characters lost
[?1] lacuna, extent stated in approximate number of characters lost

[ - $\left.\_\right]$lacuna, metre of lost text indicated in prosodic notation

[abc] lacuna, text confidently restored by editor (obvious from context or parallel text)

[?abc] lacuna, text tentatively restored by editor (conjecture)

editorial intervention

¡abc! sic: erroneous, non-standard or uninterpreted language marked by editor

\{abc\} superfluous text deleted by editor in curated text flagged as sic in diplomatic text

$\langle\mathrm{abc}\rangle$ text omitted by scribe and added by editor to curated text not shown in the diplomatic text

$\langle\mathrm{ab}: \mathrm{cd}\rangle \quad$ emendation, text $a b$ corrected or standardised to $c d$ by editor in curated text only the original reading is shown in diplomatic text, flagged as sic

\section{Translations}

(abc) Sanskrit words shown in translation for accuracy or to emphasise phonological aspects

... lost text

[abc] words inserted or repeated for clarification or disambiguation

abc translation based on text that is unclear or confidently restored

(abc) doubtful translation based on text that is unclear and tentatively read, tentatively restored or uncertainly interpreted

[abc] words neither present nor restored in the Sanskrit, tentatively supplied as probable context to the extant words

$\{\mathrm{ab} / \mathrm{cd}\}$ alternative translations of bitextual phrases (śleșa) the two layers of meaning may appear separately as $\{a b\}$ and $\{c d\}$ when the structure of the translation requires this

(1) corresponding verse number in the original

[1] corresponding line number in the original (rough correspondence shown only in translations of prose) 
